\title{
Finance Methods in the Automotive Sector - Business Agility in the Age of Digital Disruption
}

\author{
Jonathan Huke $^{1}$ and Patrick Siegfried ${ }^{1 *}$ \\ 0000-0003-1224-1613, 0000-0001-6783-4518
}

${ }^{1}$ ISM International School of Management, Mörfelder Landstrasse 55, 60598 Frankfurt a. M, Germany, International Management Department

\begin{abstract}
Agility and digital trends go hand in hand, but the advantages of digitalization perform a high pressure on the established automotive companies. For years now, automotive groups have no longer been innovation drivers in the industry. This status is reserved for radical companies like Tesla. But is there any chance that conservative companies will reinvent themselves, establish leaner structures and thus regain market dominance and innovation?
\end{abstract}

Keywords: Automotive sector, Business agility, Digital disruption, Lean management, Mobility as a service, Scaled agile framework, Value streams, Zero-based-budgeting
Review Article

https://doi.org/10.30939/ijastech..955551

Received 21.06.2021

Revised 13.08.2021

Accepted 25.08.2021

* Corresponding author

Patrick Siegfried

patrick.siegfried@ism.de

Address: ISM International School of Management, Mörfelder Landstrasse 55, 60598 Frankfurt a. M, Germany

International Management Department

Tel: +903122028653

\section{Introduction}

Agile thinking and acting finds its origins in software development at the end of the $20^{\text {th }}$ century. In the meantime, companies, regardless of their industry, are engaged in agility. Complex and dynamic economic conditions influence of digital disruption and changing customer needs force them to review their methods and organizational structures. Business agility is characterized by networked structures, self-organized teams and a rapid evaluation of processes and seems suitable to make companies ready for the future by providing added value to customers [1].

Business agility means reacting quickly to external influences and new requirements in the context of companies. In order to respond adequately to economic and global changes, companies need to make their project budgeting and implementation more flexible. Already in the 1930s of the last century Taiichi Ohno inventor of the Toyota production system - recognized the competitive advantage that resulted from more flexible production processes.

\section{Literature Review}

\subsection{Agility}

Agility has become increasingly important in the context of project management and business design methods since the 1990s [2]. In the meantime, it has attained the status of a buzzword and there are numerous definitions with different focus. This article refers to the term from software development, which is formulated in the agile manifesto. In this context, agility describes the ability of a company to adapt quickly to changing market conditions, which cannot be achieved through traditional project management [3]. Agile places a strong focus on speed, flexibility and proactive action [4]. Agility is also characterized by the progress achieved in short iterations, which contributes to the reduction of project risks [5].

\subsection{Lean Management Importance for the Automotive Industry}

Lean management design and optimize economic activities in a targeted manner. The two most important aspects are customer orientation and cost reduction by avoiding waste [6]. To achieve this, 
each action in lean management is based on five principles: "specify value, identify the value stream, flow, pull, pursue perfection" [7].

Customers are only willing to pay for products that add value to their lives. It is not important for the single customer, if the boundaries of time or budget are exceeded or not. Eric Ries describes that in his book "Lean startup". The purchaser does not care how many projects and initiatives it takes to produce the final product, he or she cares only for the finished and working product [8]. Lean management helps to focus on customer benefits, analyses and defines the added value the customer wants. A suitable way to visualize the process sequence is called "value stream mapping". All customer-related and supporting activities are recorded and visualized in detail. All value-adding processes are reduced to their core function and unnecessary effort is avoided [9]. The reduction of waste is the primary goal. This promotes flow and a smooth production process [10]. When we see the value stream as a chain of successive steps, the duration of each step is important to know. It's called process time. The lead time on the other hand includes handovers. Setting both in relation to each other, bottlenecks are identified. To improve, two things can be done. First, reduce the number of steps done within a value stream - as side advantage less handovers produce less mistakes. Second, reduce the time of each step - if possible. Aiming for the shortest sustainable lead time [11].

To reduce costs, both inventory and delivery times are checked. Storage space is considered avoidable as it does not create any added value. On top not used goods can be seen as cost driver. Justin-time can be considered as the primary method of material sourcing, as it hardly binds resources.

The pull principle organizes the allocation of work packages. Once a work step has been completed, the worker independently picks the next work package. This change from a push- to a pullsystem has a significant influence on the overall process time and determines the speed at which the work can be done. Preventing individual employees from processing several work packages at the same time and causing delays they are self-responsible for picking up the following.

Lean management has been used in the automotive industry for many years, developed and improved by the Toyota motor corporation [12]. It recognized the importance of continuous review and improvement. By involving employees in the evaluation process, it is possible to make the existing process chain every day more perfect. In addition, the motivation of employees is indirectly increased when processes function more smooth [13].

\subsection{Which Benefits does the Scaled Agile Framework bring?}

The Scaled Agile Framework (SAFe) has been developed by Scaled Agile Inc. and has been continuously revised and improved over the past 10 years. It combines skills from the fields of agility, lean, DevOps and helps companies achieve better business results and more collaboration through business agility [14]. In the most recent January 2020 update, the scaled agile framework links the classic hierarchy organization to a customer-focused agile network company.

$\mathrm{SAFe}$ for lean enterprises 5.0 builds on value streams and is divided into three levels: essential, large solution and portfolio. Essential helps to organize teams and team-of-teams around a value stream within an Agile Release Train (ART). It can hold between 50 to 125 employees, containing teams between 7 and 11 people [15]. The product vision comes from the business owner. The Release Train Engineer (RTE) ensures the process flow through training, coaching and support of the product management. A cadence of eight to twelve weeks ensures regular touchpoint. Through the program increment planning, everyone on the agile release train knows what the team has to achieve. The last two weeks serve as innovation- and planning-iteration. The time should be used for hackathons, training and the program increment planning [16].

The large solution layer combines many agile release trains into a solution train. Within SAFe suppliers and customers can be considered as ARTs. The benefit lays clearly in a shared goal and no lack of information in the supply chain. Every ten weeks the integrated and working product gets presented to all stakeholders, suppliers and customers [17].

The highest layer is the portfolio level. Strategic themes - coming from the enterprise itself - give the long-term vision of the company. They get translated into so called epics, which are long term initiatives. To confirm or reject their success a benefit hypothesis is formulated [18]. Because companies are complex living systems, there is not only one portfolio level. Each can be responsible for multiple value streams having their own budget [19].

With the last update to SAFe 5.0, the focus on achieving business agility has been expanded. Business agility refers to the state of a company that is able to respond to unforeseen market changes in short term with all relevant business units. Companies that missed the trend were quickly identified in the corona crisis. The companies that have successfully succeeded in transforming into business agility have switched their complete operating model from their planning process, including budgeting, to agile working methods. Achieving this competence is critical to the entrepreneurial existence in the age of digital disruption [17].

\subsection{Budgeting}

\subsubsection{Is traditional budgeting over?}

Budgeting is one of the key competencies a company needs to have. The evaluation should happen before the investment - forecast - and afterwards - report. Good budgeting brings the right amount of money to the right people at the right time. But what was true 50 years ago no longer needs to be current today. Therefore, is budgeting still one of the most important controlling processes?

Increasing complexity in large-scale machine production and the development of technology at the beginning of the twentieth century forced companies to improve the control of their resources [20]. It is the result of growing corporate structures and the resulting hierarchy [21]. Controlling revenue and expenditure, as well as 
setting up a plan for the needed workers, has become an ever-increasing task.

With traditional budgeting, a company prepares its assessment of its own market development in advance. Mostly for a twelvemonth period. As a controlling instrument, it was considered too inflexible. With increasing digitization, the controllers demands changed as well as the used methods and instruments. It was found that the less flexible and traditional budget planning was difficult to reconcile with the rapid market dynamics. Similarly, the high commitment of resources and associated personnel costs has a negative impact on balance sheets. The scaled agile framework identifies five drawbacks that result from traditional corporate budgeting:

- $\quad$ Slow, complicated budgeting process

- Lower fidelity decisions

- Temporary teams' lower overall performance

- Waiting on specialist causes delays to value delivery

- Full resource utilization is favoured over a fast flow of value" [22]

\subsubsection{The benefits of zero-based budgeting}

Both increasing globalization and the advancing networking of services and products are presenting new challenges to the global economy. Companies need to pay much more attention to how they plan and use their available resources. Disinvestment can have long-term consequences and have a lasting impact on the market position of companies. Optimized investment and better planning, distribution and control must be sought.

One way to achieve this is to provide zero-based budgeting. The prevalence of zero-based budgeting in companies has increased exponentially by $57 \%$ in recent years. This is clear from a report by Accenture strategy published in 2018 [23]. Investments are planned based on their priorities [24]. A list of the annual and longterm objectives and the related measures are brought together at the beginning. These are categorized and prioritized. In accordance with a predetermined budget, the financial resources are allocated to the individual approaches to action. The evidence-based analysis ensures that the prioritized topics are awarded the contract for financing [25]. The limited capital holds a cap on the implementation of the too many topics. Companies using zero-based budgeting has exponential increased since 2011 [23]. 48\% of companies followed their competitors and introduced this budgeting approach [23].

\section{Research Methodology and Hypothesis Development}

This paper focusses on the automotive sector, an important economic driver that will see major changes in the near future. New trends and technology like electro mobility, fuel cells, autonomous driving, car subscription models, air tax will disrupt the market from the inside as well from the outside by new competitors. In the last five years, Car-Sharing alone has recorded an increase of over 200 percent [26]. The vast majority of the society would like to see climate-friendly, zero emission and price-acceptable transport options. Until 2025 that could mean, a decrease in personal car ownership.

Hypotheses: Car manufacturers will survive the age of digital disruption if they can ensure that short innovation cycles develop tailor-made products for demanding consumers.

How companies will survive the age of digital disruption is highly connected to agile principles and practices. New budgeting models and their potential impact show the benefits of value stream financing, with a clear focus on the automotive sector.

Finally, a concept is presented that shows how a smooth implementation in corporate structures can succeed.

The theoretical basics cover agility, SAFe with the underlying principles, and budgeting possibilities. The data for these articles were collected primarily by existing literature such as white papers, books, scientific papers, and articles.

\subsection{Digital Trends and the resulting Disruption}

Knowing that agile companies are much nimbler because their plans are not set in stone. It is all the more impressive when you look at tesla's rapid response to acute customer problems. A Tesla customer texted Elon Musk via Twitter that he cannot leave his dog unattended in his car without the risk of the dog collapsing due to overheating. Shortly tesla released the "dog mode". The temperature within the vehicle stays at constant level and informs passingby people via a message on the dashboard screen that the owner is back soon.

Software dominates the world and eats it up was once the headline of an article [27]. Leading by example, tesla is seeing their self's as software company, which builds cars as a matter effect. Here the old principle applies, software sells hardware. Because of that Tesla has become the most innovative car manufacturer. Starting with the software core and building the hardware around it, it brings many advantages in the long run as the software is always easier to adapt.

The automobile was a revolution for locomotion in the late 19th century. Today's digital progress and disruption brought by software companies is comparable. Since there is a computer in every household and the internet is accessible to most of the worlds people, the world is getting connected more and more. This constant progress has noticeable effects on the economy and society. Nowadays, more people browse with their smartphones than with their Home-PC [28].

Digitalization and the resulting connection of cars among each other challenges car manufacturers. Infotainment screens will increasingly occupy more space of the driver's attention, the road won't. The smartphone will become the central point from which 
all functions will be controlled. Already it has replaced some of the specially developed navigation systems of car manufacturers. Solutions such as Apple CarPlay or Android Auto already integrate the smartphone into the car, barrier-free. That happens with a cable or even without. The driver does not lack any known comfort. The software is always available after a one-time purchase [29]. This also has advantages on the aftermarket, when unlocking the already existing feature only takes a click. It is easy to see, that car manufacturers should aim for aftermarket upgrades. The next mobility news website identifies the digital cockpit, electrification, autonomous driving and connected cars as the four next and future trends in the automotive sector [30].

The vehicle cockpit has been continuously expanded with new technical solutions in recent years. Touch screens and gesture control are now available across manufacturers. Driving assistants facilitate daily driving by adaptively regulating speed and taking over the steering. Due to the increasing connection of cars with each other, traffic jams are better predicted, and autonomous driving is becoming more and more safe. The driver is getting more and more decoupled from the street. Scenarios and models are being worked on in which trucks line up one after the other as if they are on rails in order to exploit the potential of the wind shadow [31]. The vehicles communicate autonomously with each other and inform themselves about obstacles on the road. One can almost speak of an improved swarm intelligence. The implementation of new digital developments and the increasing networking increase overall road safety and as a deduction the individual driving comfort.

Disruptive business models in particular are fuelled by digitisation. Uber technologies inc. has revolutionized and consistently developed the process of individual passenger transport. The original offer was limited to passenger transportation, and uber now offers - among other things - the delivery of meals and the rental of publicly accessible bicycles [32]. An example of how the value chain is expanding horizontally through digitisation. The revolutionary novelty that has given uber an advantage over the established taxi industry is still the simple and customer-oriented service. Both the order and the payment are processed via App. An innovative business model that would not have been possible without digitalization. The lack of rethinking and innovating the business model of the taxi market made it easy for uber to access and stay there. Uber was founded in 2009 but already employed 1.6 million drivers in 2016 [33]. Adapting dusty business models to today's customer needs through technology was a clear win in a saturated market. Ubers advantage was - and still is - their disruptive business model [34].

As already stated, the automotive industry lacks innovation. Only new entrants, such as Nikola Motor Company, Tesla Motors, Rimac Automobili and others, set new standards of the possible. In doing so, they are forcing the rest of the industry to rethink. Advances in the electrical \& hydrogen market are primarily not driven by established companies. Since 2020 the EU has set up regulations on fleet consumption, which are intended to help increase the supply of electric vehicles [35]. Toyota has been offering a hybrid vehicle with the Prius since 1977. In Europe - apart from the Audi duo with a number of 60 vehicles - the first hybrid 2008 in the form of the Audi Q7 was launched. The leisurely implementation of innovations cannot be solely related to the fact that trends are being overslept or not enough capital is invested in research and development.

Tesla motors now has a market capitalization of 185 billion us dollars, outnumbering all other American companies in the automotive sector. That makes tesla 2,39 times more worthy than Volkswagen [36]. The biggest German automotive company had a yearly output of 10 million cars, tesla in comparison produced only 0,37 million cars in 2019 [37]. The question about tesla's market capitalization if they only produce a third of Volkswagens output is let out intendedly.

The question arises why tesla motors and Nikola Motor Company are so committed to such a huge disruption. Why are they achieving such significant successes in an already saturated market whether they are private or commercial vehicles. It is unlikely that they will only fill the gaps left by exiting market players. Is it a unique management style or the method of budgeting?

Investing in new product ideas involves a risk that is difficult to calculate or project. It is comparable to a black box. Even if the solution is promising, the implementation is too expensive or your customer is not the core of the product. There is no guarantee that the funds invested will make a profit. This uncertainty - of course - encourages caution and let car manufacturers stick to conservative strategies.

\subsection{Currently Applied Budgeting in Automotive Companies}

Conservative established enterprises are normally subdivided according to their functional departments, so called silos. This is normal and can be attributed to historical growth. The strongly hierarchical structures result in a top-down control [38]. Historically it was an advantage. But due to today's rapidly changing conditions companies get slow without wanting it. It is not surprising that financial departments - whose task it is to prevent companies from heading for disaster by acting conservatively - change very slowly. The silo structure is deeply anchored and to a certain extent expected in the supporting role of finance departments. That supporting role let it be involved in all other departments of an enterprise.

Taking a look on the normal funding process of a new project or a companywide program, a lot of parties are involved. The more silos, the more handoffs between them. That results in more potential mistakes. Rework and adjustments lead to a steady slowdown of the overall process.

The fundamental problem of traditional budgeting is the view into the glass ball. It is usual to budget twelve months in advance. Early decisions are strategic in nature and are made centrally. But strategic decisions made too early in the innovation process, carry 
a risk. However, they carry a higher risk of negative effects as limited information is available [39]. De facto, it is impossible to make reliable statements over such a long period of time. Nobody in mid 2019 could predict a pandemic. So, companies find themselves in a quandary.

A white paper published by KPMG in 2018 sheds light on the future of zero-based budgeting in the automotive sector. Although there is already a proven application of zero-based budgeting in the consumer goods and retail sectors, the automotive industry is slowly adapting these trends [40]. In view of the changing demands on the automotive industry, innovative approaches to financial planning are needed with the aim of spreading risks and minimizing losses [41]. The winners in the automotive industry will be those companies that can quickly adapt their business models and allocate resources to strategic needs [40].

Finally, I formulate my hypotheses:

1. Business agility enables car manufacturers to survive the age of digital disruption

2. Including the customer in the research and development process will have a positive impact on customer-oriented behaviour of the automotive sector

3. Flexible budgeting and the ability to quickly change tactical direction gains a competitive advantage

\section{Results and Discussions}

Excessively high initial costs can lead to companies making financial mistakes. A simple method that can serve as use case is needed to help automotive companies. It will be easy to learn, but hard to master. Especially for conservative companies, trying to stick to the methods and process of the last century.

As baseline the house of change will serve. That will be the trickiest part. Overactive change management a lot of books have been written and many will follow. But nevertheless, the most pressing part will be the sense of urgency. Without that, companies and - more important - people will not start changing their behaviour. The core values of the agile manifesto are the foundation. Individuals and interactions, working software, customer collaboration and respondence to change build the foundation all pillars of the house of change build on [42]. All employees have to understand them and life them. Training and constant remembering will be done by the agile coach or the scrum master of the individual teams. To follow the vision of the company, we need four pillars to build the roof on. All milestones have to be centralized and can't be subdivided to individual teams. Decisions have to be data driven. That requires a huge technical integration and data or cloud-architects. All teams are built out of different silos, to achieve a crossfunctional view. The fourth and last pillar decouples the control of financiers from the innovators. Success can only be brought by people, how are not tighten to rigid grids. The shared goal consists of a clear product vision and the willing to make an impact as company and individual.

Centralized milestones help creating team spirit, especially when trying to achieve a shared goal. This goes hand in hand with leadership skills. Motivated employees become followers of the vision [43].

Data driven decision making has many advantages compared to decisions based on gut feeling. It shows that companies have a productivity increase by $4-6 \%$ [44]. The tricky part of it, nevertheless, remains the data. The rule is - shit in, shit out. So, where do we get the reliable data from? We must raise them by ourselves. Through self-created metrics, we can change raw data - mostly from soft factors - into usable hard facts. For example, data such as design decisions can be validated. Potential customers are presented with two design concepts via an A/B-test and can evaluate them. On a scale of one to five, this results in a mean value that is empirical and comparable. This gives - in this example the designers - a better insight into customer acceptance of their intended end product. The same method applies to investing strategies. Here also data-driven decisions discourage companies from investing in concepts or products that are not very promising. In the long run this pays off due to right investments.

To build good products, you need motivated employees. This is clear, but companies are traditionally built in silos. This means that people with the same skills and similar tasks work with or among each other. For example, the classic departments Finance, Human Resources, Production. As already described in this article, the goal of agile teams is to break down these silos to bring together the best possible knowledge per team. Furthermore, teams should exist in the long run.

The last pillar of the house drawn here is about the separation of innovation and conservative employees in the finance department. Of course, you can't blindly throw money into the Research \& Development department and hope that something useful will come out of it. It is more about the appropriate management of innovation budgets. This means that it is not the development itself that is "financed", but the people. For example, an MVP is priced at the beginning of the ten-week cycle. On the cost side, this includes personnel costs, material costs, etc. Conversely, the expected added value that can potentially be generated is also priced. So, if the ten-week investment yields an assessable MVP, the proven innovation can be evaluated, and a decision made whether it is the right product or at least the right direction.

The roof is the shared goal. Only with it can the entire company and all its teams head towards a single goal. It also promotes cohesion within the company because the employees feel part of something bigger.

So how do we know where to start? Value Stream Mapping offers us a solution. As already described, we map the value chain in order to deal with the individual process steps and improve them. A positive effect of the recognition and active use of the value streams is also that the Research \& Development department can 
insert its final product into it. The early integration into the supply chain avoids errors in the later production. Furthermore, it can be excluded that for example changes have to be made to the production chain. If you have to rely on a specific supply chain, this can prove to be a great advantage.

Cross-company agility is an issue that many people are biting their teeth on. One reason for this is the lack of commitment from higher management. The teams need the buy-in to be able to develop further. But not only that. Agile developments have much more potential when the way is paved for cross-team organisation. Last but not least, a shared goal is needed for this. The best framework to act agile across organisations is offered by Scaled Agile Inc. with its Framework. The ten-week integration points offer a continuous and equally rapid opportunity for the company to adapt to new external influences and - if necessary - to change course. In a fast moving, technology dominated world like ours, this provides a massive advantage over the competition. The ten weeks are each divided into five two-week iterations. Our research and development Value Stream, however, has another milestone in its programme increases. Within the IP iteration the meeting takes place which decides whether the MVP will continue or be abandoned. The pivot-or-persevere-meeting.

The Lean start up cycle provides a structure to make decisions. In the Research \& Development area it is particularly important to decide whether to continue financing a new product or not. Companies can see in the development process whether customers will accept the product or whether it can be integrated into existing production processes. Therefore a few tools are presented here to support this process. Furthermore, it remains to say that the decisions should not be made from the gut but should be based on data collected within the company. In the beginning all available data will be reviewed and checked. How big was the investment of the last ten weeks? A comparison with the forecast ten weeks ago indicates the reliability of the team. It also helps to make future forecasts more accurate, for example by pricing in risk buffers. A projection of costs and revenues over the next ten weeks provides information on the relevance of the product. Comparisons of increases and decreases in costs show how far the development has progressed. Regular contact with customers is important. Even more important is the feedback they give. Are we moving in the right direction? Does it reflect current market interests? The survey should have taken place before the meeting. The principle applies - "data rules". The people who help develop the product remain a decisive factor in the war. This means that special attention must be paid to this. Culture fit is important and helps in the long run. But having the right skills available at the right time is crucial for progress. Accordingly, (1) a close relationship should be maintained with Human Resources to assist in active search and recruitment for roles, or (2) a Human Resources employee becomes part of the team to extend the cross-functionality, or (3) a team within the Value Stream, while consisting only of Human Resources employees, is fully responsible for the program and supports the other teams. Once we have all the data available, it is still necessary to decide whether the chosen path is the right one. If the MVP does not yet fulfil the requirements and cannot yet prove or disprove the hypothesis, the decision is made whether to continue or not. If the answer is no, the product is written off. If the product is behind schedule, but very promising, further research will be carried out. Subsequently, what can be achieved in the next ten weeks will be worked out. The weighted-shortest-job-first (WSJF) concept provides support in prioritisation. Depending on the maturity of the product, it may make sense to involve suppliers in the process. This can pay off in the long run.

It is imperative that all data be collected scientifically. People tend to have a good gut feeling, but in this case, they do not decide for themselves alone, but are also responsible for the jobs of many employees. Evidence based data therefore is recommended.

In summary, the following measures are suggested:

1. The same values determine the corporate culture as a basis

2. A shared goal is established

3. Define Value Streams

4. Use SAFe program increments

5. MVPs serve as unit of measure

6. Pivot-or-persevere-decision making

\section{Conclusion}

This article focuses on critically examining new concepts of budgeting in agile companies in the age of digital disruption. On the basis of this requirement, the following three hypotheses were formulated, which had to be answered in the context of this work:

1. Business agility enables car manufacturers to survive the age of digital disruption

2. Including the customer in the research and development process will have a positive impact on customer-oriented behaviour of the automotive sector

3. Flexible budgeting and the ability to quickly change tactical direction gains a competitive advantage

The chapter of the theoretical foundations has presented different approaches and framework conditions of agile concepts. The current situation shows that many companies are facing the challenges of digital disruption. The biggest task is to constantly provide innovative approaches to withstand the market turbulence and to survive the age of digital disruption [45].

The first finding, obtained from the analysis of the current state of affairs, clearly shows that traditional budgeting models are too inflexible to adequately guarantee financing in the dynamic market 
environment. A corporate culture characterized by long and complicated budgeting processes prevents innovation and provides information about success and failure very late. In addition, it has been shown that car manufacturers are confronted with new concepts of mobility and that the business models in force up to now will no longer be profitable in the future. The presented concept illustrates how car manufacturers can shape the market of tomorrow by implementing a new way of developing products and a new way of financing the innovation by focusing on customer needs. This requires a fundamental change in the corporate culture.

The increasingly complex, connected and digital world is creating new concepts for mobility. Under the pressure of disruptive business models, innovation in the automotive sector is becoming more important than ever. The first revolutionary innovation is the reorientation to the maximum added value of the customer. Constant validation of products and innovations is carried out through different channels of social media, but also through customer feedback. Another identified innovation driver is the freedom of design of our own employees to be regained. Streamlining processes and eliminating full utilization of employees help to promote crossfunctional teams and decentralized decision-making. The iterative approach drives innovation. This gives lean portfolio management more freedom to focus on strategic issues. The resulting shift from control and power within the company to employees is a very decisive step on the way to business agility.

Even large and therefore often sluggish car manufacturers can regain flexibility by changing their budgeting. Future success, however, depends on redistributing responsibility, funding value streams, and drastically reducing planning periods to a ten-week cycle. The validation of new initiatives on the basis of leading indicators provides early information on success. The maxim of action is to identify customer benefits, implement them and be faster than the competitors.

Business agility is the prerequisite to survive the age of digital disruption and helps to build a competitive advantage.

\section{Abbreviations}

\begin{tabular}{|l|l|}
\hline ART & Agile Release Train \\
\hline DevOps & Development \& Operations \\
\hline EU & European Union \\
\hline MVP & Minimal Viable Product \\
\hline PC & Personal Computer \\
\hline RTE & Release Train Engineer \\
\hline SAFe & Scaled Agile Framework \\
\hline WSJF & Weighted Shortest Job First \\
\hline
\end{tabular}

\section{Conflict of Interest Statement}

We declare that there is no conflict of interest in the study.

\section{CRediT Author Statement}

Patrick Siegfried: Conceptualization, Formal Analysis, Supervision,

Jonathan Huke: Conceptualization, Writing-original draft, Validation

\section{References}

[1] Siegfried, P. Corporate Strategic Management in practice AVM Akademische Verlagsgemeinschaft München 2017.

[2] Siegfried, P. Knowledge Transfer in Service Research - Service Engineering in Startup Companies EUL-Verlag 2014.

[3] Preußig, J. Agiles Projektmanagement: Scrum, Use Cases, Task Boards \& Co. Freiburg: Haufe Lexware GmbH 2018:2.

[4] Brown, J. L. \& Agnew, N. M. Corporate agility. Business Horizons 2018: pp. 29 - 33.

[5] Siegfried, P. Die Unternehmenserfolgsfaktoren und deren kausale Zusammenhänge Zeitschrift Ideen- und Innovationsmanagement, Deutsches Institut für Betriebswirtschaft $\mathrm{GmbH} /$ Erich Schmidt Verlag 2015: p. 131-137. DOI: https://doi.org/10.37307/j.21983151.2015.04.04

[6] Siegfried, P. Business Cases Internationalisation Strategies in Global Player Companies: Volume 1 AVM Akademische Verlagsgemeinschaft München 2015.

[7] Womack, J. P. \& Jones, D. T. Lean Thinking-Banish Waste and Create Wealth in your Corporation. Journal of the Operational Research Society 2003: p. 1.

[8] Ries, E. The Lean Startup. 2 Hrsg. New York: Penguin Random House 2017.

[9] Martin, K. \& Osterling, M. Value Stream Mapping. 2 Hrsg. New York: McGraw-Hill Education 2013.

[10]Reinertsen, D. Managing the Design Factory. 2 Hrsg. Amsterdam: Amsterdam University Press 1997.

[11]Münster, G. \& Vestin, U. Improving product flows in order to reduce order-to-delivery lead times 2012. [Online] Available at: https://pdfs.semanticscholar.org/4dca/350b34b2f86f2a574b5753a70ee6fae70c3e.pdf

[12]Teich, S. T. \& Faddoul, F. F. Lean Management - the Journey from Toyota to Healthcare. Rambam Maimonides Medical Journal 2013: p. e0007.

[13]Hopp, W. J. Positive lean: merging the science of efficiency with the psychology of work. International Journal of Production Research 2018: pp. 398 - 413.

[14]Scaled Agile $\quad$ Framework $2019 \quad$ [Online] Available at: https://www.scaledagileframework.com/about/

[15]Scaled Agile Framework Agile Release Train 2020 [Online] Available at: https://www.scaledagileframework.com/agile-releasetrain/

[16]Scaled Agile Framework Innovation and planning iteration 2019 [Online]

Available at: https://www.scaledagileframework.com/innovationand-planning-iteration/

[17]Scaled Agile Framework Solution Train 2019. [Online] Available at: https://www.scaledagileframework.com/solution-train/ 
[18]Scaled Agile Framework Enterprise 2020. [Online] Available at: https://www.scaledagileframework.com/enterprise/

[19]Scaled Agile Framework Lean Budgets 2020. [Online] Available at: https://www.scaledagileframework.com/lean-budgets/

[20] Griffin, C. E. Wholesale organization in the automobile industry. Harvard Business Review 1925: pp. 424 - 435.

[21]Eversheim, W. Prozeßorientierte Unternehmensorganisation. 2 Hrsg. Berlin: Springer-Verlag 2013.

[22]Scaled Agile Framework Strategic Themes 2020. [Online] Available at: https://www.scaledagileframework.com/strategicthemes/

[23] Timmermans, K. \& Abdalla, R. Accenture 2018. [Online] Available at: https://www.accenture.com/_acnmedia/PDF-71/Accenture-ASZBx-Anthem-POV-final.pdf\#zoom $=50$

[24]McNally, J. S. Zero-Based Budgeting. Pennsylvania CPA Journal 2017: pp. $37-42$.

[25]Timmermans, K. \& Roark, C. The Zero-Based Mindset. CFO 2019: pp. 18 - 19.

[26]Statista $\quad \mathrm{GmbH} 2020 . \quad$ [Online] Available at: https://de.statista.com/statistik/daten/studie/324692/umfrage/carsharing-nutzer-in-deutschland/

[27]Andreessen, M. WSJ $2011 . \quad$ [Online] Available at: https://www.wsj.com/articles/SB10001424053111903480904576512250915629460

[28]Valentine, O. Global Web Index Blog 2017. [Online] Available at: https://blog.globalwebindex.com/chart-of-theday/smartphone-importance-continues-increase/

[29]Anon. Apple CarPlay in BMWs Automotive News 2019: p. 35.

[30]Kuther, T. next-mobility news 2019. [Online] Available at: https://www.next-mobility.news/die-wichtigstentrends-in-der-automobilindustrie-im-jahr-2019-a-816853/

[31]Murgia, M. Britain leads the world in putting driverless vehicles on the roads 2016. [Online] Available at: https://www.telegraph.co.uk/technology/2016/04/10/britain-is-head-and-shoulders-above-rivals-in-putting-driverless/

[32]Carson, B. Uber's Secret Gold Mine Forbes 2019: pp. 32 - 34.

[33]Helft, M., Ohnsman, A. \& Solomon, B. Uber's bold move. Forbes 2016: pp. 58 - 74.

[34]Barbour, O. \& John, L. Embracing Solutions-Driven Innovation to Address Institutional Voids. California Management Review 2019: pp. 31 - 52.

[35]Pöttering, H. G. \& Nečas, P. Die EU-Verordnungen zur Verminderung der CO2-Emissionen von Personenkraftwagen und leichten Nutz$\begin{array}{lll}\text { fahrzeugen } 2018 . & \text { [Online] }\end{array}$ Available at: https://www.bmu.de/gesetz/die-eu-verordnungen-zurverminderung-der-co2-emissionen-von-personenkraftwagen-undleicht/

[36]Statista GmbH Marktkapitalisierung ausgewählter Automobilkonzerne weltweit im Jahr 2020. [Online] Available at: https://de.statista.com/statistik/daten/studie/740357/umfrage/ranking-der-wertvollsten-automobilkonzerne-weltweit/
[37] Statista GmbH Größte Automobilhersteller weltweit nach Fahr$\begin{array}{llll}\text { zeugabsatz im } & \text { Jahr } & \text { [Online] }\end{array}$ Available at: https://de.statista.com/statistik/daten/studie/173795/umfrage/automobilhersteller-nach-weltweitem-fahrzeugabsatz/

[38] Siegfried, P. International Management in Practice, Volume 1 AVM Akademische Verlagsgemeinschaft München 2015.

[39]Deshpande, A. S., Filson, L. E., Salem, O. M. \& Miller, R. A. Lean Techniques in the Management of the Design of an Industrial Project. Journal of Management in Engineering 2012: pp. 221 - 223.

[40]Simpson, C. et al. KPMG 2018. [Online] Available at: https://assets.kpmg/content/dam/kpmg/xx/pdf/2018/08/zero-basing-in-automotive.pdf

[41]Ajupov, A. A., Kurilova, A. A. \& Ivanov, D. U. Formation of Financial Planning for the Automotive Industry Mediterranean Journal of Social Sciences 2015: pp. 40 - 44.

[42]Beck, K. et al. Agile Manifesto 2001. [Online] Available at: https://agilemanifesto.org/

[43]Bourne, L. \& Walter, D. H. T. Advancing project management in learning organizations The Learning Organization Issue 11 2004: pp. $226-243$.

[44]Provost, F. \& Fawcett, T. Data science and its relationship to big data and data-driven decision making Big Data 03 2013: pp. 51 - 59.

[45]Roland Berger The dawn of the digital car. Think Act: Automotive Insights Issue 12015 : pp. 18 - 23. 